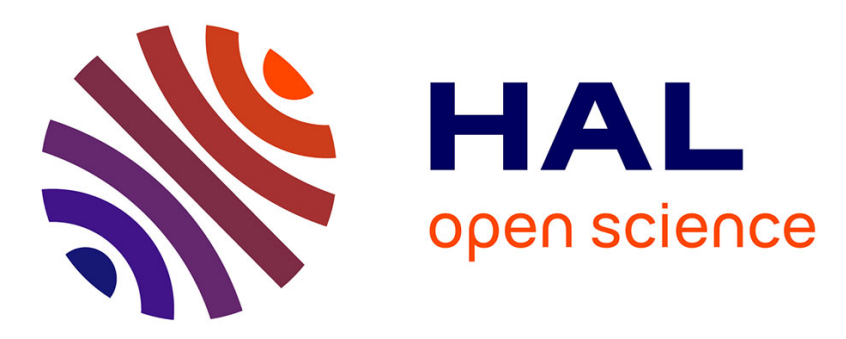

\title{
Applying the Copula Approach to Sample Selection Modelling
}

Margarita Genius, Elisabetta Strazzera

\section{To cite this version:}

Margarita Genius, Elisabetta Strazzera. Applying the Copula Approach to Sample Selection Modelling. Applied Economics, 2008, 40 (11), pp.1443-1455. 10.1080/00036840600794348 * hal-00581994

\section{HAL Id: hal-00581994 \\ https://hal.science/hal-00581994}

Submitted on 1 Apr 2011

HAL is a multi-disciplinary open access archive for the deposit and dissemination of scientific research documents, whether they are published or not. The documents may come from teaching and research institutions in France or abroad, or from public or private research centers.
L'archive ouverte pluridisciplinaire HAL, est destinée au dépôt et à la diffusion de documents scientifiques de niveau recherche, publiés ou non, émanant des établissements d'enseignement et de recherche français ou étrangers, des laboratoires publics ou privés. 


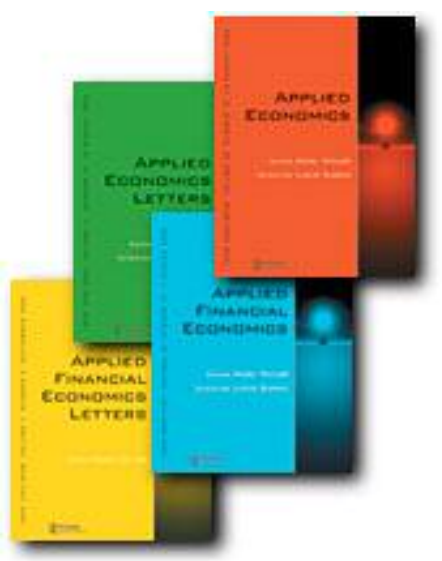

Applying the Copula Approach to Sample Selection Modelling

\begin{tabular}{|c|c|}
\hline Journal: & Applied Economics \\
\hline Manuscript ID: & APE-05-0525 \\
\hline Journal Selection: & Applied Economics \\
\hline $\begin{array}{r}\text { Date Submitted by the } \\
\text { Author: }\end{array}$ & 26-Sep-2005 \\
\hline JEL Code: & $\begin{array}{l}\text { C34 - Truncated and Censored Models < C3 - Econometric } \\
\text { Methods: Multiple/Simultaneous Equation Models < C - } \\
\text { Mathematical and Quantitative Methods, C51 - Model Construction } \\
\text { and Estimation < C5 - Econometric Modeling < C - Mathematical } \\
\text { and Quantitative Methods, Q26 - Recreational Aspects of Natural } \\
\text { Resources < Q2 - Renewable Resources and } \\
\text { Conservation|Environmental Management < Q - Agricultural and } \\
\text { Natural Resource Economics, J22 - Time Allocation and Labor } \\
\text { Supply < J2 - Time Allocation, Work Behavior, and Employment } \\
\text { Determination/Creation < J - Labor and Demographic Economics }\end{array}$ \\
\hline Keywords: & sample selection, bivariate distributions, FIML, copulas \\
\hline
\end{tabular}




\section{Applying the Copula Approach to Sample Selection Modelling}

Margarita Genius, Dept. of Economics, University of Crete, Greece

Elisabetta Strazzera, DRES and CRENoS, University of Cagliari, Italy

Corresponding author:

Prof. Elisabetta Strazzera

DRES and CRENoS

University of Cagliari

Via Fra Ignazio 78

I-09123 Cagliari

Tel +390706753763

Fax +390706753760

e-mail: strazzera@unica.it

Keywords: Sample selection, FIML, Bivariate Distributions, Copulas

JEL: C34, C51, H41, Q26

Abstract

The limited availability of tractable multivariate distributions undermines the validity of the standard parametric approach to sample selection modelling. Copula distributions can be very useful in situations where the applied researcher has a prior on the distributional form of the margins, since the modelling of the latter is separated from that of the dependence structure. The present paper first presents an application to female work data. Afterwards, the approach is analysed in an application to contingent valuation data on recreational values of forests. It is shown that the copula approach is especially beneficial in case of strong departures from the hypothesis of normality. 


\section{Introduction}

Endogenous sampling is a pervasive problem in applied microeconometrics. In an extensive survey on the topic of sample selection modelling, Vella (1998) affirms that "the ability to estimate and test econometric models over nonrandomly chosen sub-samples is unquestionably one of the more significant innovations in microeconometrics". While progress in the econometric analysis and treatment of sample selection cannot be denied, the debate is still open on what is the best procedure to be followed to obtain robust estimates from sample selection models.

In general, Full Information Maximum Likelihood (FIML) estimates are recognized as the most efficient, as long as the underlying models are correctly specified. The proviso is important, since FIML sample selection models are typically based on the assumption of bivariate normality of the joint distribution, which implies that the marginals are themselves univariate normals. Unfortunately, this assumption can often be seen as unduly restrictive: this is, in general, the case for the two fields of application chosen in the present paper to illustrate the copula approach to sample selection, i.e. models of labour supply, and models of contingent valuation.

Sample selection issues arise in the context of labour supply because not all individuals participate in the labour market. In this context, Heckman et al. (2001) suggest that since the wage density tends to be fat tailed, "the family of Student- $t_{v}$ distributions offers an attractive and potentially more appropriate class of models for the treatment parameters than those implied by the benchmark Normal model".

In contingent valuation studies selectivity may be induced by people refusing to state, or deliberately misrepresenting, their reservation price for the good under analysis. The estimates of Willingness To Pay (WTP) based on the truncated sample of valid responses may be biased. Sample selection models can be used to detect and correct selectivity bias generated by protest behaviour: see Donaldson et al. (1998), Alvarez-Farizo et al. (1999), Kontoleon and Swanson (2002), Strazzera 
et al. (2002, 2003). The Heckman's sample selection model might not be considered suitable in many applications, as the WTP distribution is generally non-normal: skewed and platikurtic distributions often provide a better fit to the data.

In an effort to attain more flexibility in sample selection modelling, a conspicuous stream of research has focused on non-parametric or semi-parametric methods, which do not require stringent distributional assumptions. Unfortunately, semiparametric methods impose some costs: for example, the intercept in the outcome equation is not identified, and its estimation requires additional procedures (such as those proposed by Heckman, 1990, or Andrews and Schafgans, 1996). Estimation of the covariance matrix of the parameters is more demanding than in the parametric case (see Vella, 1998, pp. 143-44). Furthermore, the choice of the bandwidth can affect the resulting estimates: in particular, problems of overfitting have been reported when crossvalidation techniques are used in conjunction with kernel estimates (Mroz and Savage 1999), and this is especially so in two-stage estimation problems. On the other hand, if no cross-validation or optimal criteria are used to select the bandwidth, then many estimation rounds using different bandwidths are needed to ensure the resulting estimates do not differ drastically across bandwidths.

Another path of research maintains the parametric structure of the standard Heckman's model, but allows for other distributional assumptions. Early works in this direction are Olsen (1980) and Lee (1982, 1983), who propose two-step methods where the assumption of normality is relaxed into an assumption of linear relationship between the disturbances. Of particular interest for our paper is the FIML model suggested by Lee in the same papers cited above $(1982,1983)$. It is shown that the FIML approach could be maintained even in presence of a non normal joint distribution: all that is needed is that the econometrician knows (or, has good priors on) the non normal distributions generating the errors. It is sufficient to apply the inverse standard normal distribution function on the non normal marginals to transform them into normal variates, so that the bivariate normal 
(BVN) distribution can be safely applied. This procedure is a particular case of the copula approach suggested by Smith (2003) to model sample selection using a FIML framework and relaxing the restrictive BVN distributional assumption of the standard Heckman's model.

Broadly speaking, a copula is a function that links separately specified marginals into a multivariate distribution on $[0,1]^{\mathrm{n}}$. The copula representation of the multivariate distribution allows different specifications for the marginals and greater flexibility in the specification of the dependence, therefore bypassing some of the limitations of bivariate normality mentioned above. As will be seen in the course of the paper, this is especially useful in situations where the researcher might have some prior knowledge of the marginal distributions and also when asymmetry and/or fat tails in the bivariate distribution are suspected.

A limitation of the aforementioned Lee's copula is that while allowing great flexibility in the specification of the marginals, it still restricts the type of dependence to linear correlation, and the resulting distribution may still be unsuitable to fit the data. This could prove to be crucial in cases where dependence other than linear correlation exists, since the lack of the latter could lead to the erroneous conclusion that no sample selection bias exists. Other copulas, allowing a wider range of dependency patterns, would be more appropriate in such cases. Smith (2003) indicates a special class of copulas, namely the Archimedean copulas, easy to implement and quite flexible to fit a variety of distributional shapes.

In this paper, we first show how the copula approach works when the assumption of normality of the joint distribution is patently violated. It is a labour supply application, based on Martins' (2001) work on female labour participation and wages. The copula parametric approach is compared to the Heckman's FIML, and to the semiparametric 2-step method that Martins uses to correct selectivity bias in the wages estimates. 
Next, we examine a case where departure from normality is only slight. We use contingent valuation data on recreational values of forests, published by Strazzera et al. (2003). They estimated a sample selection model using both the Heckman's FIML and 2-step methods, which we now compare to the results obtained from the copula approach.

The paper is organized as follows: the next section describes the copula models and their application to the sample selection problem; section 3 shows how the copula approach works in comparison to the standard Heckman's FIML model, and the semiparametric method on female labour data. The fourth section is devoted to the application of the copula approach to contingent valuation data on the recreational value of forests, characterized by selectivity bias due to protest responses to the WTP question. Several models are estimated, allowing testing of different dependence structures and distributional assumptions for the marginals. Section 5 concludes the paper.

\section{The Copula Approach to Sample Selection}

The structure of the sample selection model (in its simplest parametric form) is a two-equation system: the first equation is the

Selection equation

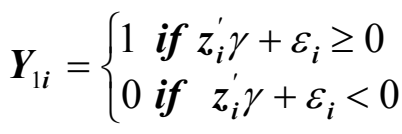

which determines the observability or not for all the members in the sample of the second equation, the Outcome equation

$\boldsymbol{Y}_{2 i}=\boldsymbol{x}_{i}^{\prime} \beta+\boldsymbol{u}_{\boldsymbol{i}}$ 
where $Y_{2 \mathrm{i}}$ is the dependent variable of principal interest, which is observed only when $Y_{1 i}=1 ; x_{i}$ and $z_{i}$ are vectors of exogenous variables; $\beta$ and $\gamma$ are vectors of unknown parameters; $\varepsilon_{\boldsymbol{i}}$ and $\boldsymbol{u}_{\boldsymbol{i}}$ are error terms with zero mean.

Knowledge of the joint distribution of $\left(u_{i}, \varepsilon_{i}\right), H$, allows writing the log-likelihood of the full ML model as

$\boldsymbol{l}=\sum_{\boldsymbol{Y}_{1 i}=0}\left(1-\boldsymbol{I}_{\boldsymbol{i}}\right) \ln \boldsymbol{F}\left(-\boldsymbol{z}_{i}^{\prime} \gamma\right)+\sum_{\boldsymbol{Y}_{1 i}=1} \boldsymbol{I}_{i} \ln \frac{1}{\sigma}\left(\boldsymbol{g}(\boldsymbol{y})-\frac{\partial \boldsymbol{H}(0, \boldsymbol{y})}{\partial \boldsymbol{y}}\right)_{\boldsymbol{y}=\frac{\boldsymbol{y}_{2 i}-\boldsymbol{x}_{i}^{\prime} \beta}{\sigma}}$

where $g$ is the pdf of $u_{i}$, and $\mathrm{F}$ is the cdf of $\varepsilon_{i}$. This model was originated in Gronau (1974) and Heckman (1974), who specified $H$ as a Bivariate Normal. This distributional assumption is still the paradigm in FIML sample selection modelling, due to ease of implementation and relative flexibility in modelling correlation ${ }^{1}$. Unfortunately, distributional misspecification will, in general, produce inconsistent estimates of the parameters: see Vella (1998) for a thorough discussion.

A recent trend is to relax the normality assumption by using semiparametric methods, which do not impose parametric forms on the error distribution. As explained in the introduction of this paper, this strategy imposes several costs. Lee $(1982,1983)$ suggests a different approach: even if the stochastic parts of the two equations are specified as non-normal, they can be transformed into random variables that are characterized by the bivariate normal distribution. This transform, which involves the use of the inverse standard normal distribution, is an example of a bivariate copula function, which is defined as follows:

Definition: A 2-dimensional copula is a function $\mathbf{C}:[\mathbf{0 , 1}]^{2} \rightarrow[\mathbf{0 , 1}]$, with the following properties:

${ }^{1}$ As opposed, for example, to the bivariate logistic that restricts correlation to a narrow range: $\left[-3 / \pi^{2}, 3 / \pi^{2}\right]$. 
For every $\boldsymbol{u} \in[0,1], \boldsymbol{C}(\boldsymbol{0}, \boldsymbol{u})=\boldsymbol{C}(\boldsymbol{u}, \boldsymbol{0})=\boldsymbol{0}$;

For every $\boldsymbol{u} \in[0,1], \quad \boldsymbol{C}(\boldsymbol{u}, 1)=\boldsymbol{u}$ and $\boldsymbol{C}(1, \boldsymbol{u})=\boldsymbol{u}$;

For every $\left(u_{1}, v_{1}\right),\left(u_{2}, v_{2}\right) \in[0,1] \times[0,1]$ with $u_{1} \leq u_{2}$ and $v_{1} \leq v_{2}$ :

$$
C\left(u_{2}, v_{2}\right)-C\left(u_{2}, v_{1}\right)-C\left(u_{1}, v_{2}\right)+C\left(u_{1}, v_{1}\right) \geq 0 .
$$

The last condition is the two-dimensional analogue of a nondecreasing one-dimensional function.

The theoretical basis of multivariate modeling by copulas is provided by a theorem due to Sklar (1959).

\section{Sklar's Theorem}

Let $\boldsymbol{H}$ be a joint distribution function with margins $\boldsymbol{F}_{1}$ and $\boldsymbol{F}_{2}$, which are, respectively, the cumulative distribution functions of the random variables $\boldsymbol{x}_{1}$ and $\boldsymbol{x}_{2}$. Then there exists a function $\boldsymbol{C}$ such that $\boldsymbol{H}\left(\boldsymbol{x}_{1}, \boldsymbol{x}_{2}\right)=\boldsymbol{C}\left(\boldsymbol{F}_{1}\left(\boldsymbol{x}_{1}\right), \boldsymbol{F}_{2}\left(\boldsymbol{x}_{2}\right)\right)$, for every $\boldsymbol{x}_{1}, \boldsymbol{x}_{2} \in \overline{\boldsymbol{R}}$, where $\overline{\boldsymbol{R}}$ represents the extended real line. Conversely, if $C$ is a copula and $\boldsymbol{F}_{1}$ and $\boldsymbol{F}_{2}$ are distribution functions, then the function $H$ defined above is a joint distribution function with margins $\boldsymbol{F}_{\mathbf{1}}$ and $\boldsymbol{F}_{2}$.

Since the copula function "links a multidimensional distribution to its one-dimensional margins" (Sklar, 1996), the name "copula" (connection) is explained. The parametric copula approach ensures a high level of flexibility to the modeler, since the specification of the margins $\boldsymbol{F}_{\boldsymbol{1}}$ and $\boldsymbol{F}_{\boldsymbol{2}}$ can be separated from the specification of the dependence structure through the function $C$ and an underlying parameter $\theta$, which governs the intensity of the dependence ${ }^{2}$.

The aforementioned Lee's inverse normal transformation corresponds to specifying a bivariate normal copula with non-normal margins. Although it is computationally straightforward, and flexible in the specification of the marginals, its use in empirical work has been relatively scant: the reason may be that the type of dependence allowed for by this copula is restricted to linear

\footnotetext{
${ }^{2}$ The present work only deals with parametric copulas.
} 
correlation. Other copula functionals allow greater flexibility in the dependence structure. In consideration of their simple mathematical structure, Smith (2003) advocates use of Archimedean copulas for application to selectivity models.

Archimedean copulas are functions generated by an additive continuous, convex decreasing function $\varphi$, with $\varphi(1)=0$. If, in addition, $\varphi(0)=\infty$, the generator is strict. In general, Archimedean copulas have the following form:

$\varphi\left(C_{\theta}(u, v)\right)=\varphi(u)+\varphi(v)$

The additive structure of copulas in this class makes estimation of the maximum likelihood, and calculation of the score function, relatively easy. Furthermore, the family is sufficiently large so as to allow a wide range of distributional shapes (right or left skewness, fat or thin tails, etc.).

Another characteristic of copulas that can be valuable to the applied researcher is the capability of accommodating both positive and negative dependence. Copulas ranging from the lower Fréchet bound (perfect negative dependence as $\theta \rightarrow-\infty$ ) to the upper Fréchet bound (perfect positive dependence as $\theta \rightarrow \infty$ ) are said to be comprehensive. A measure of dependence commonly used in econometrics applications is linear correlation; however, this measure is valid only when dealing with elliptical copulas (such as the BVN). Alternative measures of dependence include Kendall's $\tau$ $\left(\mathrm{K}_{\tau}\right)$ and Spearman's $\rho\left(\mathrm{S}_{\rho}\right)$, which are measures of concordance ${ }^{3}$. The former is defined as follows:

$$
\boldsymbol{K}_{\tau}=\boldsymbol{P}((\boldsymbol{X}-\tilde{\boldsymbol{X}})(\boldsymbol{Y}-\tilde{\boldsymbol{Y}})>0)-\boldsymbol{P}((\boldsymbol{X}-\tilde{\boldsymbol{X}})(\boldsymbol{Y}-\tilde{\boldsymbol{Y}})<0) .
$$

Another expression for $\mathrm{K}_{\tau}$ is in terms of copulas (see Nelsen, cit., p. 129):

$$
\boldsymbol{K}_{\tau}=4 \iint_{[0,1]^{2}} \boldsymbol{C}(\boldsymbol{u}, \boldsymbol{v}) d \boldsymbol{C}(\boldsymbol{u}, \boldsymbol{v})-1
$$

\footnotetext{
${ }^{3}$ Other measures of dependence rely on the criterion of dependence between random variables: for a definition, see Nelsen (1999) p. 170.
} 
that is the expression we will use to compute it when a closed form expression is not available. The measure proposed by Spearman is given by

$$
\boldsymbol{S}_{\rho}=3\left(\boldsymbol{P}\left((\boldsymbol{X}-\tilde{\boldsymbol{X}})\left(\boldsymbol{Y}-\boldsymbol{Y}^{\prime}\right)>0\right)-\boldsymbol{P}\left((\boldsymbol{X}-\tilde{\boldsymbol{X}})\left(\boldsymbol{Y}-\boldsymbol{Y}^{\prime}\right)\right)<0\right)
$$

where $(\boldsymbol{X}, \boldsymbol{Y}),(\tilde{\boldsymbol{X}}, \tilde{\boldsymbol{Y}})$ and $\left(\boldsymbol{X}^{\prime}, \boldsymbol{Y}^{\prime}\right)$ are three independent random vectors with a common distribution function $H$ whose margins are $F$ and $G$.

Also in this case we have a copula expression:

$$
\boldsymbol{S}_{\rho}=12 \iint_{[0,1]} u v d C(u, v)-3
$$

For continuous random variables the above measures are measures of concordance, which implies that they take values in $[-1,1]$, taking the value zero when we have independence (see Nelsen, cit., p. 136 for a definition of concordance measure). Spearman's $\rho$ can be interpreted as a correlation coefficient between the cdfs of the two variables. We recall that the linear (or Pearson) correlation is not a measure of dependence: for example, $\boldsymbol{\rho}(\boldsymbol{x}, \boldsymbol{y})=0$ does not imply independence of the two variables.

The table below gives the functional form of selected copulas:

$* * * * * * *$ Insert Table I*******

It can be observed that the FGM copula allows only for a limited degree of dependence (Kendall's $\tau$ is restricted to $[-2 / 9,2 / 9]$ and Spearman's $\rho$ to $[-1 / 3,1 / 3])$, which reduces its appeal for use in applications. Similar considerations hold also for the AMH, whose range for Kendall's $\tau$ is restricted to $[-0.181,0.333]$ and for Spearman's $\rho$ to $[-0.271,0.478]$. In contrast, the Frank and Plackett copulas are comprehensive, including the lower and upper Fréchet bounds and the independent copula. They both are symmetric, with thinner (Plackett) or fatter (Frank) tails than the 
BVN. In some applications symmetry may be an undesirable feature, and asymmetric copulas may be preferred. The Clayton copula exhibits asymmetry in the sense that there is a clustering of values in the left tail of the joint distribution: exactly the opposite to the Joe copula, which exhibits a strong clustering of values in the right tail. The Gumbel copula is similar to the Joe, but with a thinner tail. Unfortunately, the last three copulas, just as the most part of Archimedean copulas (one exception is the Frank copula), are monotonic: they cannot accommodate negative dependence. Figures 1 and 2 show the plots of some copulas (Clayton, Lee, Gumbel, Joe) based on standard Normal and Logistic marginals, and the BVN standard model.

\section{Sample selection modelling on female labour supply data}

In a study published by the Journal of Applied Econometrics (2001) Martins applies both parametric and semiparametric methods to the estimation of the participation and wage equations for married women in Portugal. The author shows that the 2-step semiparametric estimator is more efficient than the parametric ML estimator. The parametric model is based on a wrong assumption of bivariate normality for the joint distribution function: testing for normality of residuals in the participation equation leads to rejection of the hypothesis. Estimation of a 2-step semiparametric model is shown to produce more efficient estimates. In the following we show how the copula approach works in this context.

The data set is a sample from the Portuguese Employment Survey, interview year 1991. The sample used in the analysis consists of 2339 observations on married women, 1400 of whom were employed. Martins estimates a participation equation, regressing the dependent variable (which takes a value 1 if the woman participates in the labour force, and zero otherwise) on the following regressors: AGE (age in years), AGE2 (age squared), EDU (years of education), CHILD (the number of children under 18 in the household), YCHILD (number of children under the age of 3) LHUSWG (log of husband's wage). The outcome equation regresses the log of wages on the 
following variables: PEXP (potential experience years, calculated as age-edu-6), PEXP2 (PEXP squared), PEXPCHD (PEXP multiplied by CHILD), PEXPCHD2 (PEXP2 multiplied by CHILD). The results are summarized in table 2: the first two columns contain Martins' estimates of the parametric (FIML, BVN) model and of the 2-step semiparametric model, respectively in the first and in the second column. The standard errors reported in table 2 for the BVN model are calculated from the inverse of the computed Hessian, and differ slightly from those reported by Martins, apparently calculated from the cross product of the first derivatives. In the selection equation, the husband's wage seems to have no significant effect on the decision to participate in the labour market, while in the wage equation the only coefficient that is significant at the $5 \%$ level is the educational attainment. Martins shows that the HH test (Horowitz and Härdle, 1994) rejects the Probit for the participation equation at the 5\% level at bandwidth greater than 0.55 , and argues that a semiparametric approach can be useful to overcome the misspecification problem. The estimates of the selection equation parameters in the semiparametric model can be obtained up to a factor of proportionality (i.e. one of the coefficients is normalized to one), so they are not directly comparable to the competing models; it can be noticed however that the coefficient of the husband wage becomes significant in the semiparametric model. Focusing on the wage equation, significant estimates are obtained for the educational level and the two variables related to potential experience, while the $5 \%$ level of significance is not attained for the two interaction terms between potential experience and children.

The 2-step semiparametric estimator is in general less efficient in comparison to the FIML estimator, provided the latter is correctly specified. We show now how the copula approach allows fairly easy estimations while relaxing the distributional assumptions imposed by the standard method, based on the BVN distribution. As a first step, the margins should be specified, based on some explorative analysis of the data, or theoretical priors. For the selection equation, applying the $\mathrm{HH}$ test to the Logit specification, we observe that it is not rejected at the 5\% level up to bandwidth 
$\mathrm{h}=0.9$, and is not rejected at $10 \%$ level for bandwidth $\mathrm{h}=1$ : the Logistic could be a candidate for the error distribution in the participation model. For the wage equation, a Pagan-Vella (1989) test indicates a strong departure from normality, and, following Heckman's et al. (2001) line of argument, a better choice would be a Student- $t_{v}$ distribution. Thus, we estimate different copula models based on the Logistic (for the participation equation) and Student- $t_{v}$ (for the wage equation) marginals. In the last column of table 4 we report the estimates obtained from the Joe copula model. The parameter $v$ of the $t_{v}$ distribution is estimated along with the other parameters. Its value, about 3, indicates very heavy tails in the distribution: we recall that for $v=1$ the $t$ distribution is a Cauchy, while for $v>30$ it approximates a Normal. In the selection equation, the husband's wage is significant at the 5\% level; in the wage equation the two interaction terms between potential experience and children are not statistically significant, while all the other estimates are significant at the $1 \%$ level. These results are close to those obtained with the 2-step semiparametric estimator, but they have been obtained with less computations than those required by the semiparametric approach, since the latter entails approaching the estimation as a two-step procedure and trying several bandwidths both for the first step estimates and for the constant term of the wage equation. Furthermore, the copula approach allows estimation of the dependence structure, not estimated in the semiparametric model, which is important to analyse the statistical significance of the self selection effect (especially when the FIML BVN model does not produce a reliable estimate of the selection parameter). Also, observing the level and sign of the selection parameter may be useful for the interpretation of the self-selection process.

The approach using copulas can very easily be implemented using any software that allows for user specified likelihood functions such as GAUSS, LIMDEP, STATA, or EVIEWS. Model selection criteria such as Akaike or tests such as Vuong (1989) can be used as an aid in selecting between any two competing models. In the example above, the Akaike and Schwarz information criteria which use a penalization for the number of parameters in a model as well as the Vuong test favor the Joe 
copula with logistic and $t_{v}$ marginals over the standard bivariate normal model (Vuong's statistic is 8.7 and the test is asymptotically normal).

\section{Sample Selection Modelling on Contingent Valuation Data}

In the following we present an application of the copula approach to the analysis of data on recreational benefits provided by forests and woodlands in Scotland. The study was conducted by the Queens University Belfast, and published by Strazzera, Genius, Hutchinson and Scarpa in Environmental and Resource Economics (2003).

The questionnaires were administered on-site in selected forest and woodlands sites used for recreation, through face-to-face interviews. Individuals were asked various questions aimed at conveying information about their demographic and socio-economic characteristics, interests and hobbies, previous excursions to forests, and details on the present visit. Afterwards, they were asked if they would be willing to pay a given entry fee (bid) to the forest, were this the only possibility to maintain public access to the forest. The fee was supposed to be paid by the respondent for each person in the party. The initial bid amounts $t$ used were uniformly distributed across visitors, and were chosen on the basis of initial estimates of the WTP distribution obtained from extensive pilot studies. Next, individuals were asked the exact amount they would be willing to pay as an entry charge to the forest for each component of the party.

Table 3 gives summary statistics for the data used in this analysis: mean and standard deviation of the covariates for the full sample, and for the sub-sample of non protesters. Full descriptions of these variables are given in an Appendix. It can be seen that there are 535 protest responses, which amounts to $18 \%$ of the sample. 
The models are estimated using different covariate specifications related to the effect of socioeconomic or personal characteristics, such as income, education, age, sex; or features of the visit, such as the number and age of components of the party, expenses for parking or food, activities engaged in during the visit, previous visit experiences.

We first estimate a standard FIML model, based on the assumption of bivariate normality of the joint distribution: column 1 of Table 4 reports the parameter estimates for the best fitting regressions for the two equations (participation and valuation), selected by means of likelihood ratio tests for nested specifications from more comprehensive models. The explanatory variables in the participation equation are: the amount the individual was asked to pay at the first stage of the elicitation process (i.e. the bid multiplied by the number of people in the party); the number of visits to the forest where the interview took place, or to other forest sites during the past year; time spent in the forest; parking expenditure; income (class 2); and a dummy variable indicating whether the individual was alone or in a party when visiting the forest. It can be observed that higher tendered bids induce a higher probability of a protest response. People who frequently visit forests are also more probably protesters, and this can be explained as a reaction to the reallocation of their property rights (in the Coasian sense). On the other hand, people who spent more time in the forest are less likely to protest, as well as people who paid a parking fee for the current visit, while the effect of income is not clear-cut.

The valuation equation specifies $\log$ WTP as the dependent variable. The results indicate a standard downward sloping demand curve (more frequent visitors to the forest are willing to pay less per visit). Time spent at the site and the appreciation of the recreational benefits given by the forest have, as expected, a positive effect. Also parking expenditures are positively correlated with 
stated WTP, and this can be easily explained by considering that the object of the elicitation question was a ticket inclusive of parking fees. Income has also the expected effect since the lower income categories are willing to pay less on average; males are willing to pay more than females. The negative estimate for the coefficient of Children seems to indicate that respondents placed lower values for children in their party; but the effect must be somehow counter-balanced, since the coefficient estimate for party size close to one indicates that there is some proportionality between the total amount the respondent is willing to pay and the number of people in the pool.

Although this model does not show evident symptoms of misspecification (namely, instability of the coefficient estimates, and the correlation coefficient close to its boundary), we wish to investigate the tenability of the assumption of bivariate normality for the joint distribution. The following step involves the analysis of the distributional specification of the two margins. As in the previous case, both the Horowitz (1993) and Horowitz and Härdle (1994) tests are applied to check the normality assumption for the selection equation. For the valuation equation we apply the Pagan-Vella test for normality. The results of the latter (F-statistic: 2.81) would lead to rejection of the hypothesis of normality for the valuation equation at a $1 \%$ level of significance, though not at a $5 \%$ level of significance. The $\mathrm{HH}$ test does not reject the probit model for the participation equation at all selected bandwidths; the Horowitz test at bandwidth $\mathrm{h}=1$ rejects the Probit (Figure 1), while at the same bandwidth the Logit is not rejected (Figure 2).

After estimating the model under different distributional specifications (Normal, Logistic, Extreme Value) for either margin, we select the logistic-logistic specification as the one giving the best fit as measured by the Akaike and Schwarz criteria. The last columns of Table 4 report results for the best fitting model, i.e. the Joe copula, which under all distributional assumptions performed better than the competing models. Its opposite, the Clayton copula, is also reported for demonstrative purposes. We also show results for the Lee copula, since it is fairly well known in the econometrics literature: recent applications include Von Ophem (2000) and Heckman et al. 
(2001). Parameter estimates do not change dramatically across copulas, but it can be observed that for most parameters the Joe and the Clayton copulas show departures in opposite directions from the benchmark estimates. The estimate of $\theta$ in the Clayton copula, and its associated standard error, would indicate lack of dependence; however, this is due to the fact that the type of left tail clustering assumed by this copula is not compatible with our data, and the value of the loglikelihood confirms the relatively bad fit. The parameter $\theta$ is not directly comparable across copulas, but Kendall's $\tau$ and Spearman's $\rho$ are. The Akaike and Schwarz criteria indicate the Joe copula, which exhibits the highest degree of dependence, as the best fitting model. However, unlike the first application, in this case the Vuong test fails to reject the BVN model: the fitted Joe copula is in fact quite similar to the fitted BVN distribution, as the plots in Fig. 5 show.

Table 5 reports the estimates and confidence intervals for the measures of central tendency of WTP, obtained from the BVN and the Joe copula with Logistic marginals. Since the parameter estimates do not differ much across models, the mean and median values estimates obtained from them are also very close. The plots reported in Figure 5 are useful to explain this result: while the fitted Joe copula exhibits some skewness and fatter tails with respect to the fitted BVN, yet the divergence is not dramatic. Using the copula approach when there is a weak departure from normality of the joint distribution would not produce major changes in the estimates, but there is some gain in precision, resulting in narrower confidence intervals.

\section{Conclusions}

The copula representation of the bivariate distribution underlying the sample selection model allows different specifications for the marginals and great flexibility in the specification of the dependence. In a recent paper, Smith (2003) suggests the use of copula functions, and in particular Archimedean copulas, to correct selectivity bias in data affected by endogenous sampling. In this 
paper we show that copula models are flexible and easy tools to deal with sample selection while improving efficiency. First, we examined a case where the data show strong departures from the hypothesis of normality. Using data published by Martins (2001), we could see that the copula approach entail efficiency gains of the parameter estimates in a full information setting, and the improvement of the overall goodness of fit with respect to the BVN model is confirmed by the Vuong's test for model selection. We then applied the copula approach to WTP data collected to assess the use value of forests for recreation. This data had been modelled in a paper by Strazzera et al. (2003) by means of standard parametric sample selection models. Here, the tenability of the assumption of bivariate normality implicit in the standard Heckman's model is checked, and it is found that the hypothesis of normality for the joint distribution of errors in the outcome equation could be rejected, even though the departure from normality is not strong. The copula approach is applied to analyse different hypotheses on both the dependence structure and the distributional shape of the margins. Several copula models were estimated, and the best fitting model was a Joe copula, i.e. a model suitable for asymmetric, right-tailed joint distributions, linking two logistic distributions. However, the Joe copula and the BVN model are nearly equivalent, as indicated by the result of the Vuong selection test. As it perhaps could be expected, in this case the advantage of using the copula approach instead of the standard Heckman's model is not as important as in the case of strong departures from normality, even though it allows some gain in the precision of the estimates.

\section{References}

Alvarez-Farizo B, Hanley N, Wright RE, MacMillan D. (1999) Estimating the Benefits of AgriEnvironmental Policy: Econometric Issues in Open-Ended Contingent Valuation Studies. Journal of Environmental Planning and Management 42: 23-43.

Andrews DWK, Schafgans MMA. (1998) Semiparametric Estimation of a Sample Selection Model. Review of Economic Studies 65: 307-45. 
Donaldson C, Jones AM, Mapp T, Olson JA. (1998) Limited Dependent Variables in Willingness to Pay Studies: Applications in Health Care. Applied Economics 30: 667-77.

Gronau R. (1974) Wage Comparisons - A Selectivity Bias. Journal of Political Economy 82: 1119-1144.

Heckman J. (1974) Shadow Prices, Market Wages, and Labor Supply. Econometrica 42: 679-693.

Heckman, J.J. (1990) Varieties of Selection Bias, American Economic Review, 80: 313-318.

Heckman J, Tobias JL, Vytlacil E. (2001) Simple Estimators for Treatment Parameters in a Latent Variable Framework with an Application to Estimating the Returns to Schooling. NBER working paper W7950.

Horowitz JL. (1993) Semiparametric estimation of a work-trip mode choice model. Journal of Econometrics 58: 49-70.

Horowitz JL, Härdle W. (1994) Testing a parametric model against a semiparametric alternative. Econometric Theory 10: 821-848.

Kontoleon A, Swanson TM. (2003) The WTP for Property Rights for the Giant Panda: Can a Charismatic Species be an Instrument for Nature Conservation? Land Economics 79: 483-99.

Lee LF. (1983) Generalized Econometric Models with Selectivity. Econometrica 51: 507-12.

Lee LF. (1982) Some Approaches to the Correction of Selectivity Bias, Review of Economic Studies 49: $355-372$.

Martins Fraga M. (2001) Parametric and Semiparametric Estimation of Sample Selection Models: An Empirical Application to the Female Labour Force in Portugal. Journal of Applied Econometrics 16: 23-39.

Mroz TA, Savage TH. (1999) Overfitting and Biases in Nonparametric Kernel Regressions Using Cross Validated Bandwidths: a Cautionary Note. Working paper, University of North-Carolina, Chapel Hill, 99-10.

Nelsen RB. (1999) An Introduction to Copulas. Lecture Notes in Statistics. New York: SpringerVerlag.

Olsen R. (1980) A Least Squares Correction for Selectivity Bias. Econometrica 48: 1815-1820.

Pagan AR, Vella F. (1989) Diagnostic Tests for Models Based on Individual Data: A Survey. Journal of Applied Econometrics 4 Supplement: S29-S59.

Sklar A. (1959) Fonctions de Répartition à N Dimensions et Leurs Marges. Publ. Inst. Statis. Univ. Paris 8: 229-231.

Sklar A. (1996) Random Variables, Distribution Functions, and Copulas - a Personal Look Backward and Forward, published in: Distributions with Fixed Marginals and Related Topics, 
edited by L. Rüschendorf, B. Schweizer, and M.D. Taylor, Institute of Mathematical Statistics, Hayward, CA.

Smith MD. (2003) Modelling Sample Selection Using Archimedean Copulas. Econometrics Journal, 6: $99-123$.

Strazzera E, Scarpa R, Calia P, Garrod G, Willis K. (2003) Modelling Zero Values and Protest Responses in Contingent Valuation Surveys. Applied Economics 35: 133-38.

Strazzera E, Genius M, Scarpa R, Hutchinson G. (2003) The Effect of Protest Votes on the Estimates of Willingness to Pay for Use Values of Recreational Sites. Environmental and Resource Economics 25: 461-476.

Vella F. (1998) Estimating Models with Sample Selection Bias: A Survey. The Journal of Human Resources 33: 127-169.

Vuong QH. (1989) Likelihood Ratio Tests for Model Selection and Non-Nested Hypothesis. Econometrica 57: 307-333. 
Table 1. Functional form of Copulas

\begin{tabular}{|c|c|c|c|c|}
\hline Family & $C(u, v)$ & Range of $\theta$ & $\begin{array}{l}\text { Range of } K_{\tau} \\
\text { and } S_{\rho}\end{array}$ & $\theta_{\text {indep }}$ \\
\hline Product & $u v$ & & 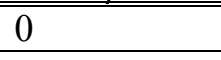 & \\
\hline Lee* & $\Phi_{2}\left(\Phi^{-1}(u), \Phi^{-1}(v) ; \theta\right)$ & {$[-1,1]$} & {$[-1,1]$} & 0 \\
\hline Clayton & {$\left[u^{-\theta}+v^{-\theta}-1\right]^{-1 / \theta}$} & $(0, \infty)$ & {$[0,1]$} & $0^{+}$ \\
\hline Frank & 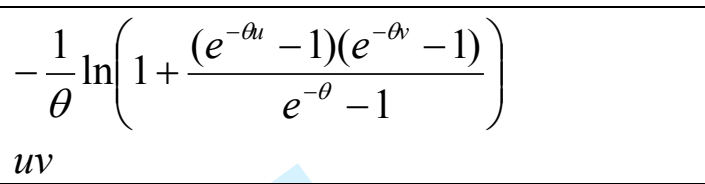 & $\begin{array}{l}(-\infty, \infty) \backslash\{0\} \\
0\end{array}$ & $\begin{array}{l}{[-1,1] \backslash 0} \\
0\end{array}$ & 0 \\
\hline Gumbel & $\exp \left(-\left((-\ln u)^{\theta}+(-\ln v)^{\theta}\right)^{1 / \theta}\right)$ & {$[1, \infty)$} & {$[0,1]$} & 1 \\
\hline Joe & $1-\left((1-u)^{\theta}+(1-v)^{\theta}-(1-u)^{\theta}(1-v)^{\theta}\right)^{1 / \theta}$ & {$[1, \infty)$} & {$[0,1]$} & 1 \\
\hline $\mathrm{AMH}$ & $\frac{u v}{(1-\theta(1-v)(1-u))}$ & {$[-1,1)$} & $\begin{array}{l}{[-0.18,0.33]} \\
{[-0.27,0.47]}\end{array}$ & 0 \\
\hline FGM & $u v(1+\theta(1-u)(1-v))$ & {$[-1,1]$} & $\begin{array}{l}{[-0.22,0.22]} \\
{[-0.33,0.33]}\end{array}$ & 0 \\
\hline Plackett* & $\begin{array}{l}\frac{[1+(\theta-1)(u+v)]}{2(\theta-1)}- \\
\frac{\sqrt{[1+(\theta-1)(u+v)]^{2}-4 u v \theta(1-\theta)}}{2(\theta-1)} \\
u v\end{array}$ & $(0, \infty)$ & {$[-1,1]$} & 0 \\
\hline
\end{tabular}

* Non Archimedean copula 
Table 2: Estimates of BVN, 2-Step Semiparametric and Copula Models for Female Labour Participation and Wages

\begin{tabular}{|c|c|c|c|c|c|c|}
\hline \multirow{2}{*}{ Variables } & \multicolumn{2}{|c|}{ BVN } & \multicolumn{2}{|c|}{$\begin{array}{c}\text { 2-Step } \\
\text { Semiparametric }\end{array}$} & \multicolumn{2}{|c|}{$\begin{array}{c}\text { Joe: Logistic \& } \\
\text { t-Student }\end{array}$} \\
\hline & Coeff. & $\begin{array}{c}\text { (S.E.) } \\
\text { p-value }\end{array}$ & Coeff. & $\begin{array}{c}\text { (S.E.) } \\
\text { p-value }\end{array}$ & Coeff. & $\begin{array}{c}\text { (S.E.) } \\
\text { p-value }\end{array}$ \\
\hline CONST & -0.570 & $\begin{array}{c}(0.937) \\
0.539\end{array}$ & & & -0.740 & $\begin{array}{c}(1.395) \\
0.596 \\
\end{array}$ \\
\hline CHILD & -0.120 & $\begin{array}{c}(0.028) \\
0.000\end{array}$ & -0.097 & $\begin{array}{c}(0.012) \\
0.000\end{array}$ & -0.187 & $\begin{array}{c}(0.045) \\
0.000\end{array}$ \\
\hline YCHILD & -0.090 & $\begin{array}{c}(0.074) \\
0.223\end{array}$ & -0.018 & $\begin{array}{l}(0.04) \\
0.653\end{array}$ & -0.113 & $\begin{array}{c}(0.109) \\
0.301\end{array}$ \\
\hline LHUSWG & -0.100 & $\begin{array}{c}(0.077) \\
0.181\end{array}$ & -0.078 & $\begin{array}{l}(0.03) \\
0.009\end{array}$ & -0.232 & $\begin{array}{c}(0.112) \\
0.039\end{array}$ \\
\hline$E D U$ & 0.150 & $\begin{array}{c}(0.010) \\
0.000\end{array}$ & 0.086 & $\begin{array}{c}(0.012) \\
0.000\end{array}$ & 0.289 & $\begin{array}{c}(0.018) \\
0.000\end{array}$ \\
\hline$A G E$ & 0.810 & $\begin{array}{c}(0.253) \\
0.001\end{array}$ & 1 & & 1.394 & $\begin{array}{c}(0.389) \\
0.000\end{array}$ \\
\hline$A G E 2$ & -0.120 & $\begin{array}{c}(0.031) \\
0.000\end{array}$ & -0.145 & $\begin{array}{c}(0.003) \\
0.000\end{array}$ & -0.206 & $\begin{array}{c}(0.048) \\
0.000\end{array}$ \\
\hline CONST & 4.480 & $\begin{array}{c}(0.089) \\
0.000\end{array}$ & 4.800 & $\begin{array}{c}(1.700) \\
0.005\end{array}$ & 4.139 & $\begin{array}{c}(0.075) \\
0.000\end{array}$ \\
\hline$E D U$ & 0.110 & $\begin{array}{c}(0.005) \\
0.000\end{array}$ & 0.090 & $\begin{array}{c}(0.015) \\
0.000 \\
\end{array}$ & 0.133 & $\begin{array}{c}(0.003) \\
0.000 \\
\end{array}$ \\
\hline$P E X P$ & 0.130 & $\begin{array}{c}(0.058) \\
0.087\end{array}$ & 0.410 & $\begin{array}{c}(0.133) \\
0.002\end{array}$ & 0.379 & $\begin{array}{c}(0.060) \\
0.000\end{array}$ \\
\hline PEXP2 & -0.003 & $\begin{array}{c}(0.014) \\
0.875\end{array}$ & -0.060 & $\begin{array}{c}(0.030) \\
0.045\end{array}$ & -0.055 & $\begin{array}{c}(0.012) \\
0.000\end{array}$ \\
\hline PEXPCHD & 0.032 & $\begin{array}{c}(0.035) \\
0.148\end{array}$ & 0.040 & $\begin{array}{c}(0.026) \\
0.124\end{array}$ & -0.000 & $\begin{array}{c}(0.015) \\
0.977\end{array}$ \\
\hline PEXPCHD2 & -0.010 & $\begin{array}{c}(0.011) \\
0.078\end{array}$ & -0.017 & $\begin{array}{c}(0.010) \\
0.089\end{array}$ & -0.003 & $\begin{array}{c}(0.004) \\
0.489\end{array}$ \\
\hline$\sigma$ & 0.550 & $\begin{array}{c}(0.015) \\
0.000\end{array}$ & & & 0.347 & $\begin{array}{c}(0.019) \\
0.000\end{array}$ \\
\hline$\theta$ & 0.350 & $\begin{array}{c}(0.100) \\
0.000\end{array}$ & & & 2.782 & $\begin{array}{c}(0.254) \\
0.000\end{array}$ \\
\hline $\boldsymbol{K}_{\tau}$ & 0.231 & & & & 0.490 & \\
\hline$S_{\rho}$ & 0.340 & & & & 0.670 & \\
\hline$v$ & & & & & 2.953 & $\begin{array}{c}(0.320) \\
0.000\end{array}$ \\
\hline Log-lik & & & & & & \\
\hline
\end{tabular}


Table: 3. Means and standard deviations (in parenthesis) by groups of respondents

\begin{tabular}{|l|c|c|}
\hline & $\begin{array}{c}\text { FULL } \\
\text { SAMPLE }\end{array}$ & $\begin{array}{c}\text { NON } \\
\text { PROTESTERS }\end{array}$ \\
\hline $\begin{array}{l}\text { Mean WTP (£) } \\
\text { Median WTP }\end{array}$ & $\ldots$ & $4.23(3.6)$ \\
\hline Children & $0.88(1.08)$ & $0.88(1.076)$ \\
\hline Alone & $0.07(0.26)$ & $0.06(0.23)$ \\
\hline Time & $4.71(0.75)$ & $4.77(0.73)$ \\
\hline Parking & $0.23(0.48)$ & $0.26(0.51)$ \\
\hline Past & $1.51(1.35)$ & $1.39(1.23)$ \\
\hline Other & $1.40(1.26)$ & $1.35(1.22)$ \\
\hline Improved & $0.92(0.27)$ & $0.92(0.26)$ \\
\hline Income & & \\
1: $<16000$ & $0.32(0.47)$ & $0.31(0.46)$ \\
2: 16000-30000 & $0.47(0.50)$ & $0.49(0.50)$ \\
\hline Male & $0.65(0.48)$ & $0.65(0.48)$ \\
\hline Sample size & 2964 & 2429 \\
\hline
\end{tabular}


Table 4. Estimates of BVN, 2-Step parametric and Copula Models for CV Data

\begin{tabular}{|c|c|c|c|c|c|c|}
\hline Variables & BVN & $\begin{array}{l}\text { 2-step } \\
\text { param. }\end{array}$ & Joe-NN & Lee-LL & $\begin{array}{c}\text { Clayton- } \\
\text { LL }\end{array}$ & Joe-LL \\
\hline Constant & $\begin{array}{c}0.743 \\
(0.201)^{*}\end{array}$ & $\begin{array}{c}0.728 \\
(0.200)\end{array}$ & $\begin{array}{c}0.695 \\
(0.205)\end{array}$ & $\begin{array}{c}1.213 \\
(0.355)\end{array}$ & $\begin{array}{c}1.194 \\
(0.353)\end{array}$ & $\begin{array}{c}1.156 \\
(0.361)\end{array}$ \\
\hline Bid1 & $\begin{array}{c}-0.354 \\
(0.036) \\
\end{array}$ & $\begin{array}{c}-0.329 \\
(0.036) \\
\end{array}$ & $\begin{array}{c}0.358 \\
(0.035) \\
\end{array}$ & $\begin{array}{c}-0.629 \\
(0.064) \\
\end{array}$ & $\begin{array}{l}-0.595 \\
(0.066) \\
\end{array}$ & $\begin{array}{c}-0.637 \\
(0.063) \\
\end{array}$ \\
\hline Alone & $\begin{array}{c}-0.636 \\
(0.107) \\
\end{array}$ & $\begin{array}{c}-0.642 \\
(0.107) \\
\end{array}$ & $\begin{array}{c}-0.597 \\
(0.105) \\
\end{array}$ & $\begin{array}{c}-1.086 \\
(0.182) \\
\end{array}$ & $\begin{array}{l}-1.106 \\
(0.183) \\
\end{array}$ & $\begin{array}{c}-1.049 \\
(0.179) \\
\end{array}$ \\
\hline Time & $\begin{array}{c}0.193 \\
(0.039)\end{array}$ & $\begin{array}{c}0.191 \\
(0.039)\end{array}$ & $\begin{array}{c}0.201 \\
(0.040)\end{array}$ & $\begin{array}{c}0.345 \\
(0.070)\end{array}$ & $\begin{array}{c}0.341 \\
(0.069)\end{array}$ & $\begin{array}{c}0.354 \\
(0.071)\end{array}$ \\
\hline Park & $\begin{array}{c}0.584 \\
(0.094) \\
\end{array}$ & $\begin{array}{c}0.579 \\
(0.092) \\
\end{array}$ & $\begin{array}{c}0.583 \\
(0.093) \\
\end{array}$ & $\begin{array}{c}1.227 \\
(0.209) \\
\end{array}$ & $\begin{array}{c}1.208 \\
(0.207) \\
\end{array}$ & $\begin{array}{c}1.231 \\
(0.207) \\
\end{array}$ \\
\hline Past & $\begin{array}{c}-0.134 \\
(0.021)\end{array}$ & $\begin{array}{c}-0.132 \\
(0.021)\end{array}$ & $\begin{array}{c}-0.133 \\
(0.021) \\
\end{array}$ & $\begin{array}{c}-0.237 \\
(0.037) \\
\end{array}$ & $\begin{array}{c}-0.231 \\
(0.037) \\
\end{array}$ & $\begin{array}{c}-0.240 \\
(0.037)\end{array}$ \\
\hline Other & $\begin{array}{c}-0.070 \\
(0.021) \\
\end{array}$ & $\begin{array}{l}-0.075 \\
(0.022) \\
\end{array}$ & $\begin{array}{c}-0.061 \\
(0.021) \\
\end{array}$ & $\begin{array}{c}-0.116 \\
(0.038) \\
\end{array}$ & $\begin{array}{c}-0.126 \\
(0.038) \\
\end{array}$ & $\begin{array}{c}-0.104 \\
(0.038) \\
\end{array}$ \\
\hline Inc2 & $\begin{array}{c}0.168 \\
(0.057) \\
\end{array}$ & $\begin{array}{c}0.167 \\
(0.057) \\
\end{array}$ & $\begin{array}{c}0.162 \\
(0.057) \\
\end{array}$ & $\begin{array}{c}0.282 \\
(0.102) \\
\end{array}$ & $\begin{array}{c}0.284 \\
(0.102) \\
\end{array}$ & $\begin{array}{c}0.278 \\
(0.101) \\
\end{array}$ \\
\hline Constant & $\begin{array}{c}-0.666 \\
(0.113)\end{array}$ & $\begin{array}{l}-1.010 \\
(0.129)\end{array}$ & $\begin{array}{l}-0.717 \\
(0.114)\end{array}$ & $\begin{array}{c}-0.632 \\
(0.113)\end{array}$ & $\begin{array}{l}-0.543 \\
(0.113) \\
\end{array}$ & $\begin{array}{l}-0.647 \\
(0.112)\end{array}$ \\
\hline Children & $\begin{array}{c}-0.074 \\
(0.018)\end{array}$ & $\begin{array}{c}-0.086 \\
(0.018)\end{array}$ & $\begin{array}{c}-0.078 \\
(0.018)\end{array}$ & $\begin{array}{c}0.077 \\
(0.018)\end{array}$ & $\begin{array}{l}-0.074 \\
(0.018)\end{array}$ & $\begin{array}{l}-0.080 \\
(0.018)\end{array}$ \\
\hline Time & $\begin{array}{c}0.184 \\
(0.019) \\
\end{array}$ & $\begin{array}{c}0.222 \\
(0.020) \\
\end{array}$ & $\begin{array}{c}0.194 \\
(0.019) \\
\end{array}$ & $\begin{array}{c}0.181 \\
(0.019) \\
\end{array}$ & $\begin{array}{c}0.171 \\
(0.019) \\
\end{array}$ & $\begin{array}{c}0.187 \\
(0.019) \\
\end{array}$ \\
\hline Park & $\begin{array}{c}0.267 \\
(0.028)\end{array}$ & $\begin{array}{c}0.336 \\
(0.030)\end{array}$ & $\begin{array}{c}0.273 \\
(0.028)\end{array}$ & $\begin{array}{c}0.283 \\
(0.026)\end{array}$ & $\begin{array}{c}0.265 \\
(0.026)\end{array}$ & $\begin{array}{c}0.282 \\
(0.025)\end{array}$ \\
\hline Past & $\begin{array}{l}-0.115 \\
(0.012) \\
\end{array}$ & $\begin{array}{c}-0.147 \\
(0.013) \\
\end{array}$ & $\begin{array}{c}-0.121 \\
(0.012) \\
\end{array}$ & $\begin{array}{c}-0.121 \\
(0.012) \\
\end{array}$ & $\begin{array}{l}-0.111 \\
(0.012) \\
\end{array}$ & $\begin{array}{c}-0.124 \\
(0.012) \\
\end{array}$ \\
\hline Male & $\begin{array}{c}0.067 \\
(0.028)\end{array}$ & $\begin{array}{c}0.069 \\
(0.028)\end{array}$ & $\begin{array}{c}0.068 \\
(0.027) \\
\end{array}$ & $\begin{array}{c}0.078 \\
(0.027) \\
\end{array}$ & $\begin{array}{c}0.078 \\
(0.027)\end{array}$ & $\begin{array}{c}0.080 \\
(0.027)\end{array}$ \\
\hline Party & $\begin{array}{c}0.937 \\
(0.046) \\
\end{array}$ & $\begin{array}{c}0.943 \\
(0.045) \\
\end{array}$ & $\begin{array}{c}0.938 \\
(0.047) \\
\end{array}$ & $\begin{array}{c}0.938 \\
(0.045) \\
\end{array}$ & $\begin{array}{c}0.940 \\
(0.045) \\
\end{array}$ & $\begin{array}{c}0.940 \\
(0.045) \\
\end{array}$ \\
\hline Improved & $\begin{array}{c}0.190 \\
(0.050) \\
\end{array}$ & $\begin{array}{c}0.194 \\
(0.050) \\
\end{array}$ & $\begin{array}{c}0.186 \\
(0.050) \\
\end{array}$ & $\begin{array}{c}0.166 \\
(0.052) \\
\end{array}$ & $\begin{array}{c}0.160 \\
(0.052) \\
\end{array}$ & $\begin{array}{c}0.161 \\
(0.052) \\
\end{array}$ \\
\hline Inc1 & $\begin{array}{l}-0.181 \\
(0.037) \\
\end{array}$ & $\begin{array}{c}-0.175 \\
(0.037) \\
\end{array}$ & $\begin{array}{c}-0.181 \\
(0.037) \\
\end{array}$ & $\begin{array}{c}-0.183 \\
(0.037) \\
\end{array}$ & $\begin{array}{l}-0.185 \\
(0.037) \\
\end{array}$ & $\begin{array}{c}-0.183 \\
(0.037) \\
\end{array}$ \\
\hline Inc2 & $\begin{array}{c}-0.142 \\
(0.035) \\
\end{array}$ & $\begin{array}{c}-0.104 \\
(0.035) \\
\end{array}$ & $\begin{array}{c}-0.137 \\
(0.035) \\
\end{array}$ & $\begin{array}{c}0.140 \\
(0.034) \\
\end{array}$ & $\begin{array}{c}-0.152 \\
(0.034) \\
\end{array}$ & $\begin{array}{l}-0.140 \\
(0.034) \\
\end{array}$ \\
\hline$\sigma$ & $\begin{array}{c}0.649 \\
(0.011) \\
\end{array}$ & & $\begin{array}{c}0.639 \\
(0.010) \\
\end{array}$ & $\begin{array}{c}0.367 \\
(0.007) \\
\end{array}$ & $\begin{array}{c}0.364 \\
(0.008) \\
\end{array}$ & $\begin{array}{c}0.356 \\
(0.006)\end{array}$ \\
\hline$\theta$ & $\begin{array}{c}0.287 \\
(0.074)\end{array}$ & & $\begin{array}{c}1.954 \\
(0.308)\end{array}$ & $\begin{array}{c}0.337 \\
(0.078)\end{array}$ & $\begin{array}{c}0.115 \\
(0.109)\end{array}$ & $\begin{array}{c}1.760 \\
(0.193)\end{array}$ \\
\hline $\boldsymbol{K}_{\tau}$ & 0.185 & & 0.345 & 0.219 & 0.054 & 0.297 \\
\hline$S_{\rho}$ & 0.275 & & 0.491 & 0.323 & 0.081 & 0.428 \\
\hline Log-lik & -3606 & & -3600 & -3590 & -3596 & -3584 \\
\hline
\end{tabular}


Table 5: Means and Standard Deviations from BVN and Joe-LL Copula Model

\begin{tabular}{|c|c|c|}
\hline & BVN & Joe-LL \\
\hline $\begin{array}{l}\text { Mean } \\
\text { WTP }\end{array}$ & 3.518 & 3.550 \\
\hline $\begin{array}{r}\text { C.I. Mean } \\
> \\
<\end{array}$ & $\begin{array}{l}3.392 \\
3.645\end{array}$ & $\begin{array}{l}3.433 \\
3.667\end{array}$ \\
\hline $\begin{array}{l}\text { Median } \\
\text { WTP }\end{array}$ & 2.851 & 2.855 \\
\hline $\begin{array}{r}\text { C.I. Med. } \\
> \\
<\end{array}$ & $\begin{array}{l}2.739 \\
2.962\end{array}$ & $\begin{array}{l}2.762 \\
2.949\end{array}$ \\
\hline
\end{tabular}

Figure 1. Plots of BVN, Gumbel, Joe and Clayton Copulas: Normal marginals.

(a) Bivariate Normal

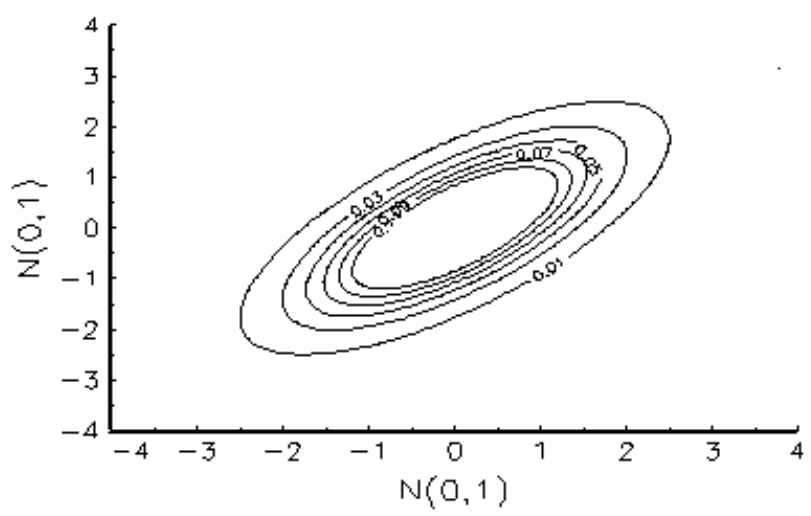

(c) Joe Copula

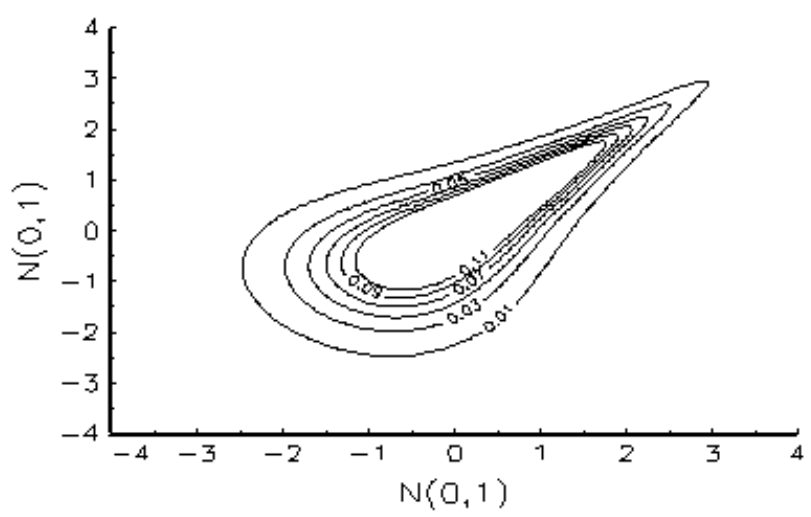

(b) Gumbel Copula

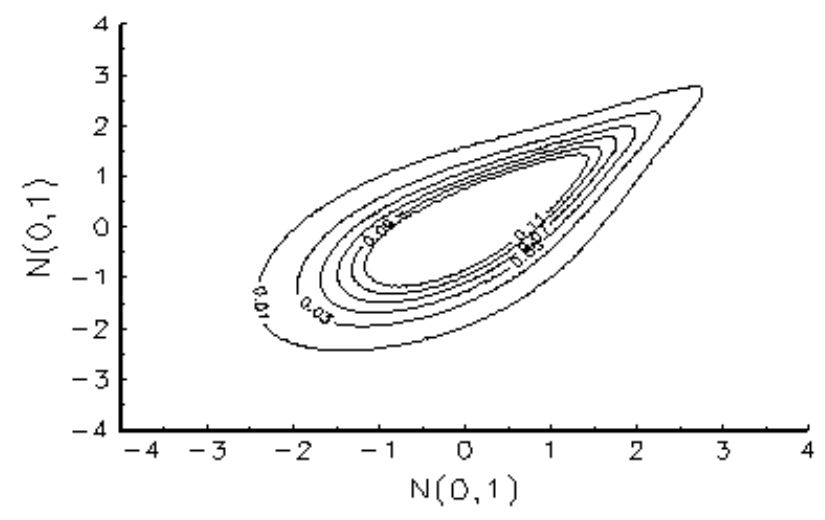

(d) Clayton Copula

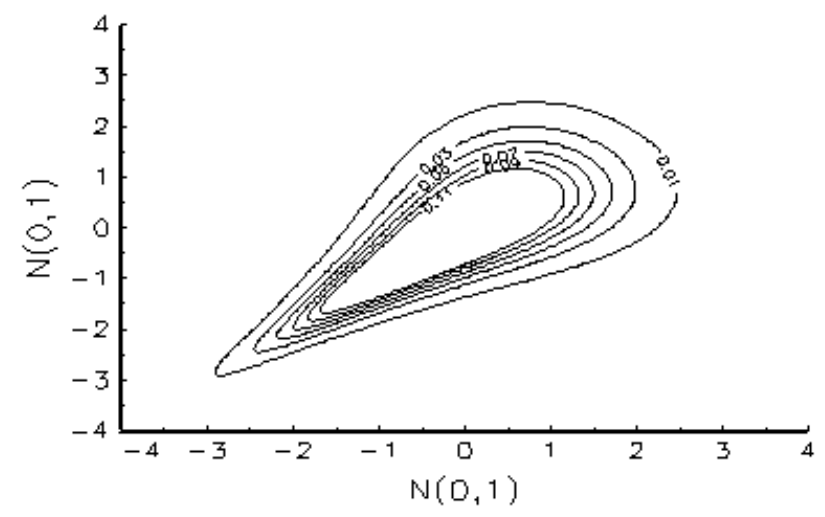


Figure 2. Plots of Gaussian, Gumbel, Joe and Clayton Copulas: Normal and Logistic marginals

(a) Goussian Copula (Lee)

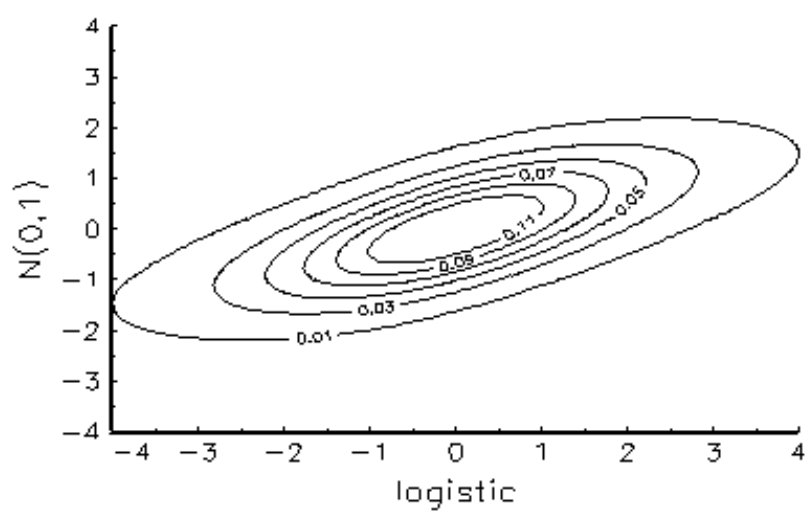

(c) Joe Copula

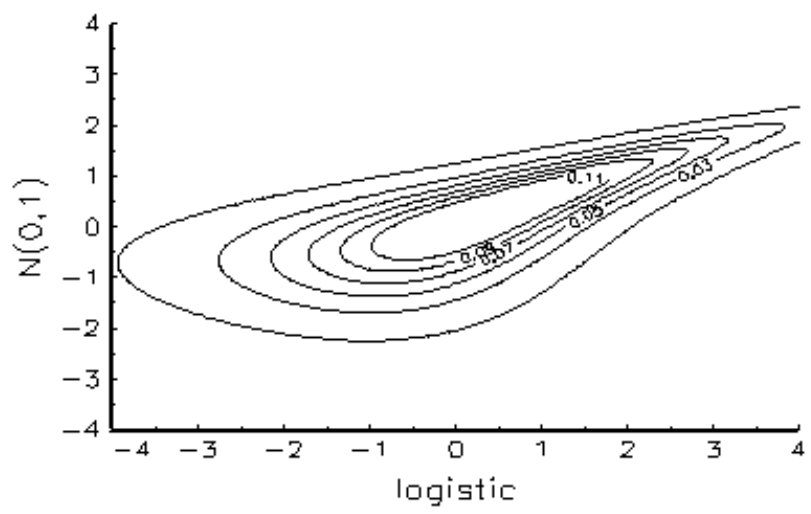

(b) Gumbel Copula

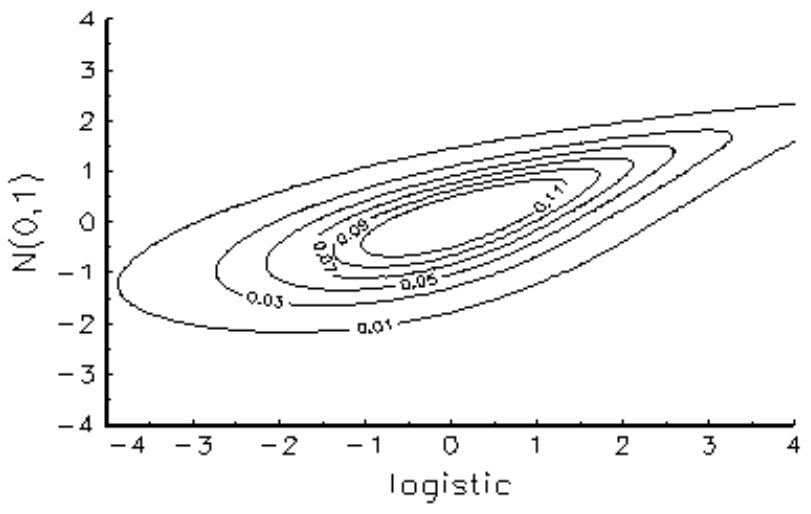

(d) Clayton Copula

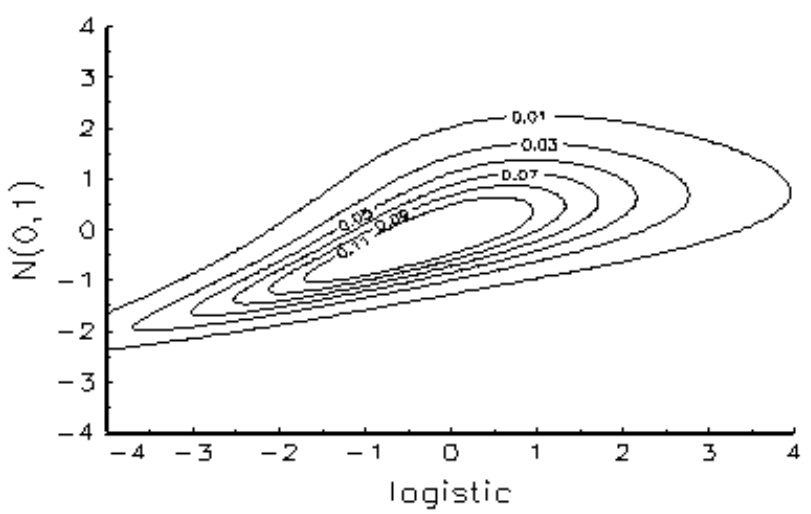


Figure 3. Horowitz test, Probit specification, bandwidth $h=1$

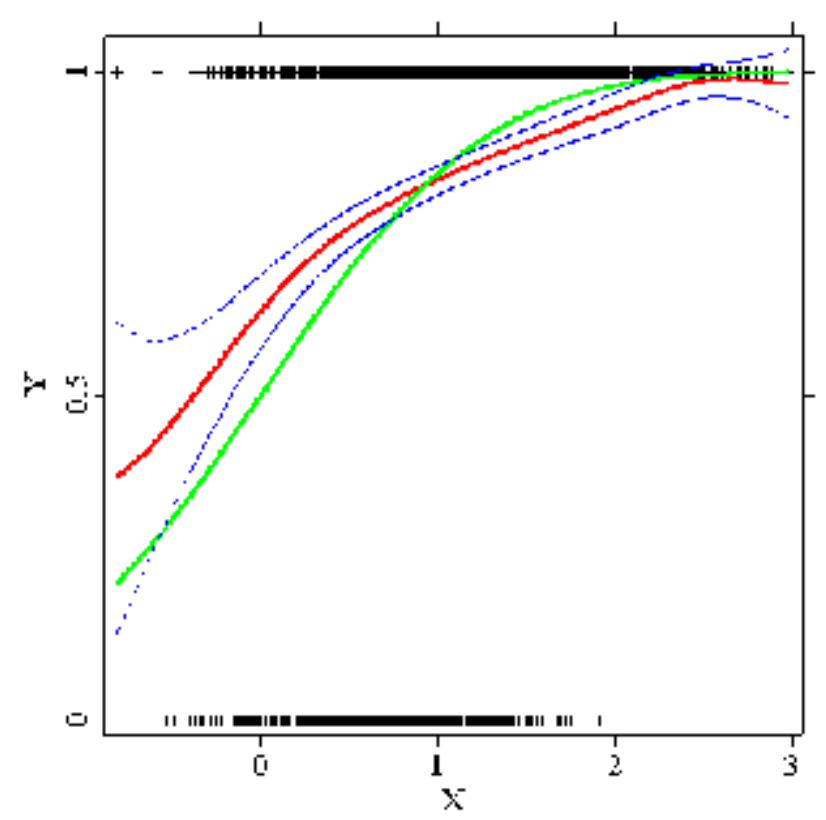

Figure 4. Horowitz test, Logit specification, bandwidth $h=1$

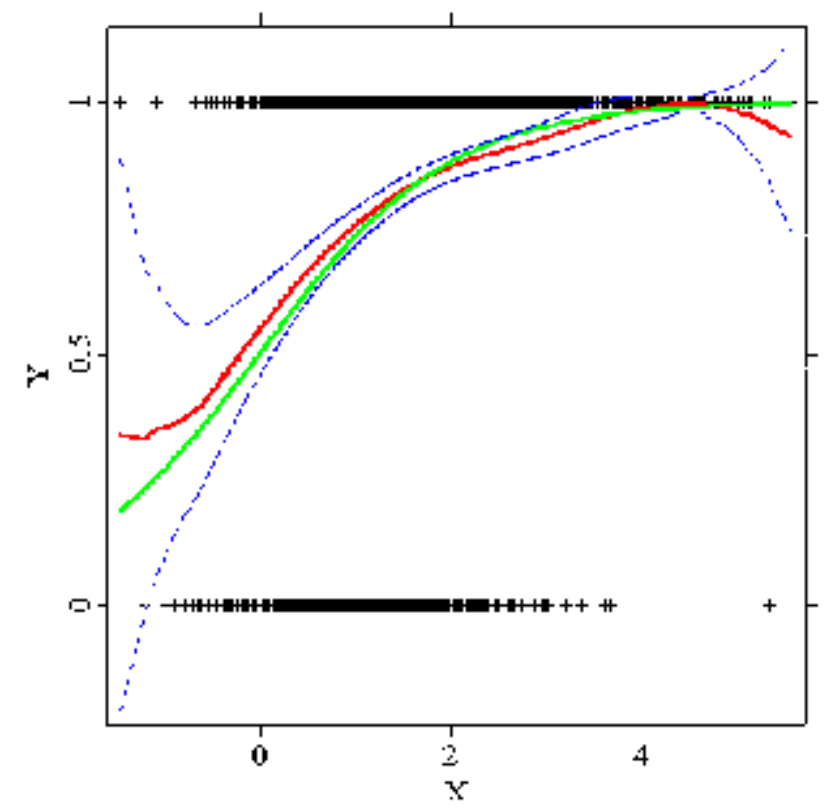


Figure 5. Plots of estimated BVN, Clayton, Lee and Joe Copula models

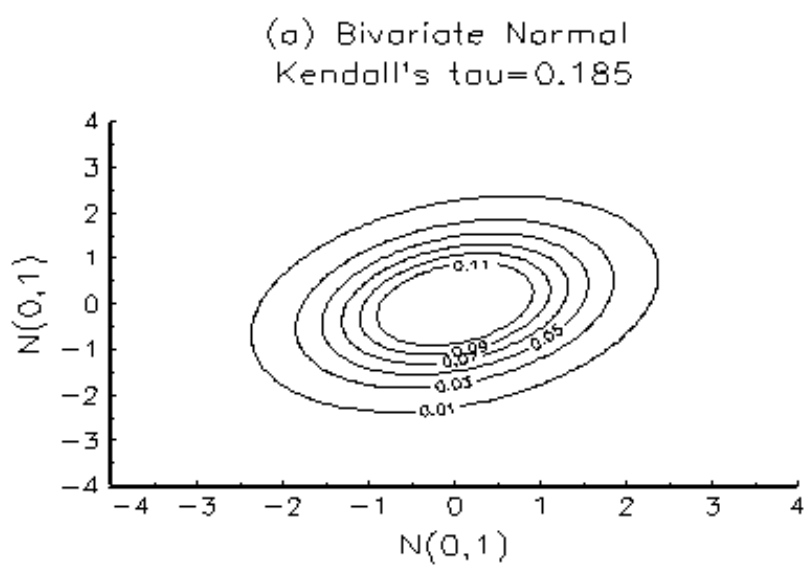

(c) Gaussian Copula (Lee) Kendall's tau $=0.22$

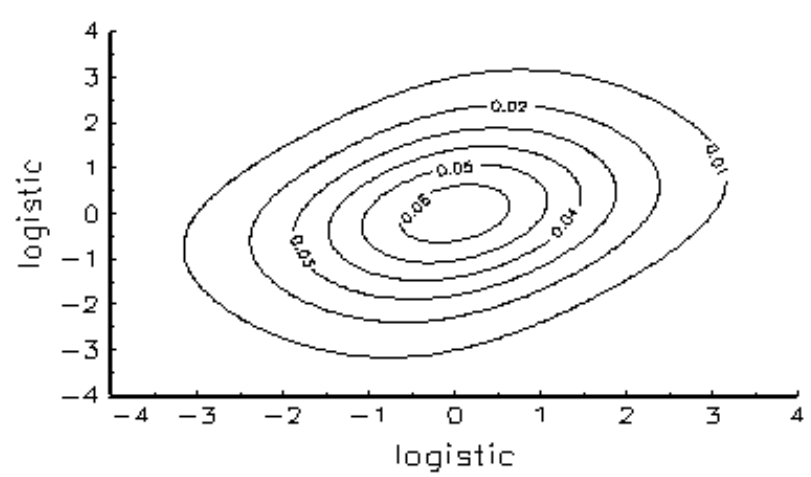

(b) Clayton Copula Kendall's tou $=0.054$

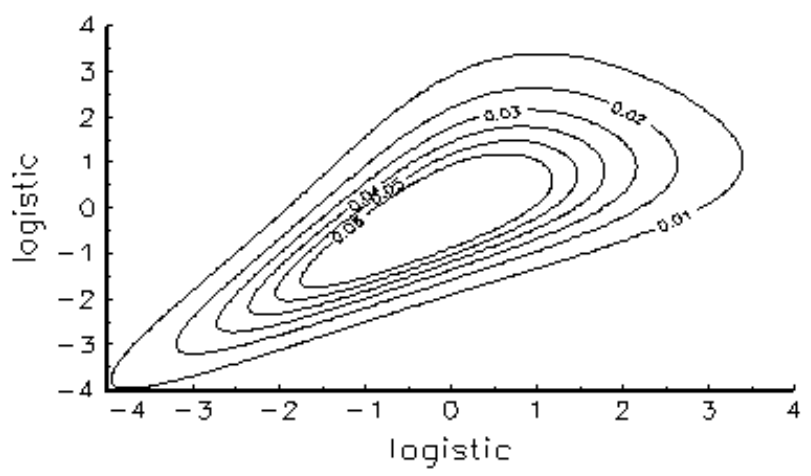

(d) Joe Copula

Kendall's tau $=0.297$

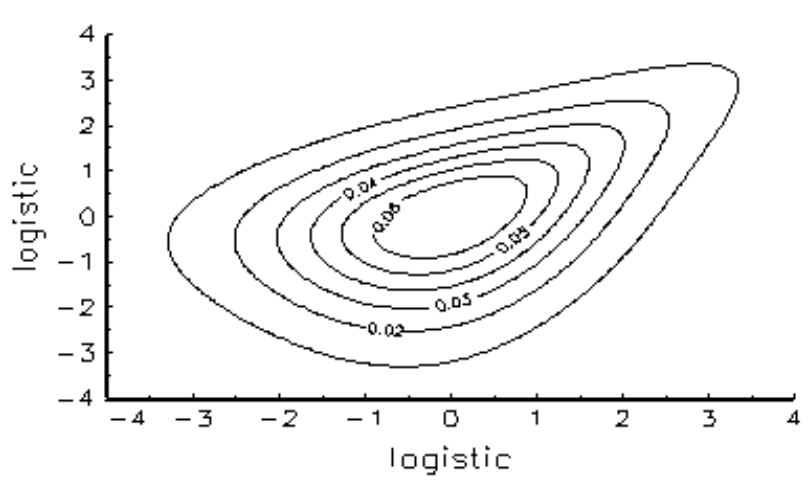




\section{Appendix}

\section{List of variables}

Wtp: total amount the respondent is willing to pay for the party, i.e. amount per party

Bid1: (log of) first bid presented to respondent

Nparty: (log of) size of the party

Children: number in party younger than 18

Adults: number of adults in party

Alone the respondent has visited the forest alone

Male the respondent is male

Time: (log of) time passed in the forest (minutes)

Parking: (log of) cost of parking (£)

Past: (log of) number of visits to the forest in the past year

Others: (log of) number of visits to other forests in the past year

Improved: the forest has improved recreation: 1-yes; 0-no

Income: Household income (£)

$$
\begin{array}{ll}
1 & <15999 \\
2 & 16000<30000 \\
3 & 30000 \text { and above }
\end{array}
$$

